\title{
Cora Sandel e a precisão linguística: As primeiras páginas de Alberte og Jakob
}

Fabiana Botrel

\section{Sarah Cecilie Margareta, Cora e Alberte}

Cora Sandel é reconhecida como um dos grandes nomes da literatura norueguesa. Sua obra não é extensa, mas desde sua estreia como romancista aos 46 anos com Alberte og Jakob, seu estilo marcante, sua sintaxe própria e a força de sua narrativa chamaram a atenção de críticos e leitores. Alberte og Jakob é o primeiro livro de uma trilogia que acompanha a personagem Alberte desde sua adolescência em Troms $\varnothing$, passando por seu amadurecimento como artista em Paris e sua vida de casada. Cora Sandel publicou mais dois romances e oito coletâneas de contos, mas a trilogia sobre Alberte é considerada o ponto alto de sua obra. O trecho aqui traduzido são as primeiras páginas de Alberte og Jakob.

Cora Sandel é o pseudônimo de Sarah Cecilie Margareta Gørwell Fabricius, nascida em 1880 em Oslo. Aos doze anos, mudou-se para Tromsø com a família. Entre 1906 e 1921 morou em Paris, onde estudou artes plásticas. Casou-se com um escultor sueco e em 1921 mudou-se com o marido para a Suécia.

O que queria era ser pintora. Levou anos para descobrir que seu modo de expressão estava nas palavras. Mas talvez tenha sido seu poder de observação, treinado durante os anos de estudo de artes plásticas, que a proveu das ferramentas

1 Formada em Comunicação Social - Jornalismo pela PUC-Minas e Master of Arts pela Bournemouth University, Inglaterra. Mora na Noruega desde 2000. Em 2013 concluiu o Author training in children's and young adult literature do Norwegian Institute for Children's Books. Estreou como autora em 2018 com o romance para jovens $O$ vestido (edições BesouroBox). Tem dois contos em norueguês publicados em revistas literárias na Noruega. 
necessárias para descrever o ser humano, seus conflitos, encontros e desencontros de forma tão precisa.

Sua estreia como escritora foi em 1922, com um conto publicado em um jornal norueguês. Foi a primeira vez que assinou como Cora Sandel, pseudônimo que a acompanharia por toda a carreira. Teve inúmeros contos publicados na imprensa norueguesa antes de se consagrar como autora com a publicação de Alberte og Jakob.

A história de sua heroína Alberte é em grande parte inspirada por suas experiências pessoais. Alberte og Jakob se passa em uma cidade do norte da Noruega. O lugar nunca é citado pelo nome, mas não há dúvida de que a pequena cidade que acorda com as badaladas do sino da igreja em uma manhã no meio do inverno, na cena de abertura do livro, é Tromsø.

\section{Edições equivocadas}

Cora Sandel foi uma autora discreta, tanto na vida privada como na escrita. Pode-se dizer que sua voz narrativa é baixa, sussurrante. E é falando baixo que a autora vai entrando e mexendo na cabeça de leitores, expressando com precisão instantes que mostram claramente nossa condição humana.

A escolha precisa das palavras e da pontuação, a sintaxe e a linguagem poética e ao mesmo tempo concreta são características marcantes na sua obra. A riqueza de seu texto está nos detalhes. É aquela pequena palavra no lugar certo, na hora certa. Tanta precisão linguística pode ser um desafio para a tradução de seus textos. Percebe-se que cada palavra e cada construção gramatical foi escolhida com cuidado, e a tradução tem que seguir esse rigor, mesmo sendo necessária a mudança da sintaxe para alcançar o mesmo sentido e naturalidade do texto original. Por isso, foi com enorme espanto que, no início do trabalho com a tradução do trecho aqui publicado, fiquei ciente de que existem enormes discrepâncias entre as primeiras edições da trilogia sobre Alberte e as edições posteriores.

Essas divergências incluem trocas e omissões de palavras e até de frases inteiras. Alberte og Jakob foi publicado pela primeira vez em 1926, Alberte og Fribeten em 1931 e Bare Alberte em 1939. A trilogia reunida foi publicada em 1941, e essa foi a última vez que Cora Sandel leu as correções. Na época a ortografia e a sintaxe do norueguês ainda eram muito influenciadas pelo dinamarquês. Em edições mais recentes, o texto foi revisado e modernizado. Erros de impressão acabaram resultando em novas palavras com ortografia semelhante. A modernização da sintaxe omitiu palavras e expressões, certas frases foram ligadas e outras foram 
retiradas, o que em alguns casos levou à mudança do sentido, ou pelo menos do efeito linguístico desejado pela autora. Esses erros, modificações e equívocos foram transferidos de uma edição para outra.

O caso mais extremo foi a retirada de um total de quatro páginas com conteúdo político em uma edição do último livro da trilogia no outono de 1941. Os parágrafos continham duras críticas aos alemães. Na época a Noruega estava ocupada pela Alemanha, e o diretor da editora estava preso por atividades antinazistas. A editora ainda não estava sob o controle alemão - o que no entanto viria a acontecer em 1942 -, então se supõe que a supressão dos parágrafos tenha sido um caso de autocensura. O mais surpreendente é que essa omissão não foi corrigida em edições posteriores à Segunda Guerra Mundial, o que resultou em duas versões do romance. Em norueguês, somente a primeira edição do livro contém as sequências censuradas. Esses trechos mostram o amadurecimento político da personagem, e sem eles o texto fica empobrecido.

Não há nenhuma indicação histórica de que a diretoria da editora ou Cora Sandel, que faleceu em 1974, soubessem das mudanças, omissões e erros na obra que foram reeditados em edições posteriores, nem mesmo da autocensura no último livro da trilogia. As discrepâncias entre as primeiras edições e as mais recentes foram descobertas apenas em 1997 por uma tradutora sueca. Ao trabalhar com uma nova tradução, Gun-Britt Sundström notou que a antiga edição sueca continha trechos inexistentes na nova edição norueguesa. Por causa dessa descoberta, a editora norueguesa resolveu publicar novamente a trilogia completa em 2002, baseando-se nas primeiras edições de cada livro, trazendo correções comentadas. A tradução do trecho aqui publicado foi feita a partir dessa edição.

Para citar um pequeno exemplo de como o sentido do texto pode mudar com a omissão de uma única palavra, o segundo parágrafo da página 19 da edição de 2002 começa com "Litt efter litt glir hun ind i en slags våken døs.", aqui traduzido como "Pouco a pouco ela desliza para um tipo de torpor consciente". Em uma edição posterior o parágrafo começa com "Litt efter glir hun inn i en slags våken døs". Aqui a repetição da palavra "litt" foi retirada. Sem ela a tradução seria "Logo depois ela desliza para um tipo de torpor consciente", o que muda completamente o sentido da frase, em especial porque a cena mostra como a personagem tem dificuldade em se livrar do frio que a tortura durante todo o dia e boa parte da noite. Ela não desliza para um torpor consciente rapidamente, como a publicação mais recente descreve. É devagar que Alberte consegue ignorar o frio e cair em um transe. A personagem fica horas deitada, enrolada sob as cobertas, antes que o calor possa aquecer seu corpo e sua alma e ela finalmente possa adormecer. 
Omissões como essa são infelizmente frequentes nas edições mais recentes de "Alberte og Jakob", que segundo a editora foi o livro que mais sofreu com as revisões e modernizações equivocadas. Faltam, por exemplo, 75 palavras e pequenas expressões, e sete frases inteiras foram suprimidas. O que se perde nessas edições é a riqueza da linguagem literária e o estilo próprio da autora.

\section{As vírgulas no caminho do tradutor}

O caso comentado acima mostra a importância da escolha da edição nas traduções de textos clássicos. Na tradução de Cora Sandel, o ideal foi utilizar uma edição baseada no texto original, não modernizado. Mas não há dúvida de que a ortografia e a sintaxe ultrapassadas, assim como a escolha de palavras que já caíram em desuso na versão original, tornam o trabalho de tradução mais árduo. O norueguês bokmål, uma das duas línguas oficiais na Noruega e a que é usada na sua forma escrita pela maioria da população, é muito próximo ao dinamarquês. No entanto, reformas ortográficas e mudanças nas regras gramaticais modernizaram a língua e a tornaram mais "norueguesa".

Um dos desafios ao traduzir textos noruegueses anteriores a essas mudanças é o uso e a colocação da vírgula. Baseadas na sintaxe do dinamarquês, aqui as vírgulas são usadas com mais frequência, em muitos casos separando os termos essenciais e integrantes de uma oração, como sujeito e predicado. Isso pode dificultar a compreensão da sentença para quem tem o português como língua materna. Vide o exemplo a seguir, em que é apresentada parte de uma oração da primeira edição, a mesma sentença em uma edição modernizada e em seguida a tradução.

- Primeira edição: "Noget, man kan holde sig til, sker omsider, ..." A vírgula depois da palavra noget separa o sujeito do predicado e dificulta a compreensão.

- Na edição modernizada essa vírgula foi retirada de acordo com as novas regras gramaticais, o que sem dúvida torna a sentença mais legível: "Noe en kan holde seg til, skjer omsider, ..."

- A tradução: "Finalmente acontece algo em que se pode confiar, ..." Aqui a tradutora teve que retirar mais uma vírgula para alcançar o efeito desejado, além de inverter a colocação dos termos da oração, o que será discuto abaixo. 


\section{Em busca da naturalidade}

Vou utilizar a mesma sentença como exemplo de um outro aspecto que encontro com frequência na tradução do norueguês para o português: a sintaxe e a ordem dos termos da oração. A minha experiência é de que o norueguês tem regras mais rígidas em relação à colocação dos termos integrantes da oração do que o português. Mas frases gramaticalmente corretas nem sempre soam naturais.

$\mathrm{Na}$ tradução do norueguês para o português, muitas vezes é preciso inverter a ordem dos termos para que o texto soe natural, como no exemplo acima. Seguindo a sintaxe do texto original, a tradução seria: "Algo em que se pode confiar acontece finalmente, ...”. A sentença não está gramaticalmente errada, mas não soa natural, o que torna a tradução equivocada. O texto original de Cora Sandel flui em sua poesia e a colocação das palavras soa natural e bela em norueguês.

\section{O inverno e o frio}

Uma peculiaridade no norueguês é o enorme vocabulário para atividades, equipamentos e vestuário de inverno - nem sempre se encontra o termo correspondente em português. Existem por exemplo várias palavras para descrever luvas. Votter ou vanter são as luvas de dois dedos: um para o polegar e o outro para os demais dedos, todos juntos. Hansker são as luvas tradicionais com lugar dedicado para cada um dos cinco dedos. Pulsvanter, que são as luvas usadas pela mulher do padeiro no livro, não têm dedos e geralmente são mais compridas, cobrindo também o pulso e parte do antebraço. Ou seja, pulsvanter aquece o pulso, a palma e o dorso da mão, mas deixa os dedos expostos, o que facilita o movimento. A mulher do padeiro não conseguiria fazer seu trabalho se estivesse usando luvas normais. Ao mesmo tempo, o fato de ela usar luvas e gorro mostra como o local está frio. Utilizar a palavra luvas sem comentário diminuiria a riqueza na descrição da cena. Para não atrapalhar o ritmo do texto com palavras em excesso, a solução foi aprofundar o sentido de pulsvanter no rodapé.

Outro exemplo é lareira. Existem diferentes tipos de lareira, cada um com um nome. No texto original a empregada acende um ovn, a mesma palavra utilizada para forno, mas que aqui, colocado em outros cômodos que não a cozinha, não tem o propósito de assar alimentos, mas apenas de aquecer o local. Lareira seria peis. A diferença é que peis é geralmente aberta. Ovn, ou peisovn, é fechado, muitas vezes embutido na parede, com uma porta de vidro ou metal. Por isso Alberte 
fala como deve ser bom acender o fogo de manhã e ver as chamas através da porta. Aqui talvez o leitor fique confuso, já que a imagem que muitos fazem de lareira é a de uma construção aberta, sem porta. Por outro lado, usar a palavra forno, que tem porta, seria ainda mais equivocado, já que no texto não se trata do forno na cozinha. 


\section{Alberte-trilogien}

Cora Sandel

\section{Alberte og Jakob}

\section{I}

Kirkeuret lyser som en måne i natten.

Det slår, og små, svake blus fødes ute i mørket og brænder mat, fortapt i dets uendelighet, ensomme og spredte.

Uret slår igjen, og de svake blus blir flere, flokker sig, danner rader og ruter. Liv rører sig mellem dem, en hestebjelde ringler, en hører kanskje en tom slæde slænge hit og dit efter hesten på en hårdtrampet vei. Etsteds går et eller andet med plask i sjøen, en kjetting rasler. Lyd av årer og knirkende tollepinner kommer opp fra mørket, en båt støter dumpt mot træverk, tunge ben i røiserter ramler indover en brygge, nogen roper noget.

Vest i fjorden uler en dampfløite. Røde og grønne lanterner kommer langsomt glidende ute fra mulmet. Det springes med trosser på Nykaien, ved Gammelkaien ringer Sørfjorddampen, som går klokken seks, hissig til avgang. Fjordgatens otte buelamper flammer bleke frem i rad, undtagen den som alltid er i stykker ved Louise i Svingen. Og vinduer, som tændes i et blink, klare og kraftig lysende firkanter, rykker op i geled, danner nye rader og ruter.

Uret slår et tungt slag hvert kvarter, fire hver time, og klokkeslettet i rasende fart efterpå. Og skrædder Kvandal, som spiller trækbasun i avholdsforeningens orkester, øver sig, før han åpner butikken. Med lange mellemrum frembringer han en ensom og skjælvende tone. De hører til morgenens faste lyd og bæres med gunstig vind helt op i Øvrebyen.

Har der vært snefald om natten, maser plogen med stort spetakkel, med seks hester, rop og piskesmeld og han Ola Paradis som høvedsmand, gjennem byen fra ende til anden. Trafikken er offisielt åpnet, det er bare værsågo at myldre og vrimle. Baker Teodorsen viser sig på sin trapp.

Man ser det ikke i dunkelheten, men man vet, at han har mel i bartene og melete bukser. Han ser op på været. Inde i butikken ordner fru Teodorsen i golfcape og pulsvanter de varme brød, som langes ind gjennem luken fra bakeriet, stiller dem på skrå i hylden. Baker Teodorsen ryster sig litt og sier brrr! Så knapper han strikkevesten om sig, griper sneskuffen i kroken ved døren og går igang med at måke vei over fortauget ut i gaten, så folk kan komme ind. 
Skrædder Kvandals musik forstummer. Skygger flir husimellem, og butikdørenes klokker ringer. I søstrene Kremers vindu rører hænder sig ordnende mellem kulørte båndruller, hatter på pinde, dåbskjoler, brude- og likpynt. Og der kommer frøken Liberg, som styrter morgentur og gamle Stoppenbrink, som går, adjunkt Bjerkem med stilebøker under armen på vei til skolen og jormor Jullum på veien hjem. En ny dag pågår, det er ikke til at ta feil av.

Det kan være mørke med nordlys og sternevrimmel, og kulde, så det skriker høit i sneen, når nogen går. Det kan være fuktig sydvest med regn, svarte gater og mulm. Da gnisler værfløien på kirketårnet, og de forgyldte kringlene utenfor bakerne Teodorsen og Øvre skrangler fælt. Det kan også være måneskin.

Men mest er det snetykke. Som avrunder, dæmper, nedstemmer alt, form, farve og lyd.

Når Alberte vågner om morgenen er hun god og varm. Det er den eneste tid på døgnet, hun ikke fryser. En stor, lun ro er i hendes lemmer, en legemlig fred, som er det beste, hun vet.

Hun ligger i sin fulde længde med benene ret ut.

Det er varmt overalt i sengen, og det er som kroppen hadde foldet sig ut, som var et skal omkring den sprængt.

Hun strækker sig, hun kjender sig rørlig og myk og har råd til at omgås letsindig med sin egen varme. Det hænder, at hun i overmot stikker en fot ut i kulden bare for at kjende den bli varm igjen, så fort hun trækker den tilbake.

Om aftenen kryper hun sammen under tæppet i timer, skakende av indre frost. Hun gjør sig så liten, hun kan, med benene trukket opunder sig og armene foldet over brystet. Oppe mellem skulderbladene sitter kulden og biter som en smerte. Hun har den $\mathrm{i}$ kroppen hele dagen, og den følger hende i seng. Hendes føtter er som isblokker, som ikke hører hende til, og hun blir stiv og lemster av den sammenkrøpne stilling.

Litt efter litt glir hun ind i enslags våken døs. Hendes krop sover, den er iskold men nummen og ufølsom. Oppe i hodet sitter hjerne og surrer med sit.

Tiden går, timer. Tvers gjennem et spinkelt væv av halvvåken drøm hører hun kirkeuret.

Plutselig kommer varmen. Den kommer som en feberglød. Hun strækker benene, det er som at slippe ut av et marterredskap - hun slapper musklene som efter en kraftanstrengelse. Som drukken ligger hun og kjender søvnen ta sig. 
Når hun vågner, lytter hun. Noget må ske, kirkeuret slå, skrædder Kvandal begynde, Sørfjorddampen ringe. Det gjælder at komme på det rene med, hvor i tiden man er, og hvorlænge man kan ligge og ha det godt. Men Sørfjorddampen ringer tre ganger, kirkeuret har den kjedelige egenskap at slå bare ett slag både første, andet og tredje kvarter, og skrædder Kvandal er sin menneskelige natur underkastet - han er ikke absolutt presis. Ja, der er morgener, da han svikter.

Noget, man kan holde sig til, sker omsider, trappen knaker under Jensine, som går ned. Så høres døren til kontoret og en fjern ramlen av kul. Jensine lægger i ovnen derinde, først der og så i spisestuen.

Alberte tænker på alle dem, som daglig får lagt i om morgenen. Rød glød gjennem en ovnsdør, den spradende lyd av ild, er det ikke symboler på al livets lykke? Varme er liv, kulde er død. Alberte er ildtilbeder i ordets fulde og primitive betydning.

Varmen gjør alt andet mulig.

Varme, og den kolde gnagingen i ryggen gir sig. Hænder og føtter får liv. Man blir frimodigere, livligere. Lemmene løser sig fra kroppen i friere og vakrere bevægelser, det er som at få et velsittende plag på sig. Man får lyst til at tale og le, og man får lyst til at sitte stille og være virksom med et eller andet.

Man er ikke længer fiolet $\mathrm{i}$ ansiktet. Man er et nyt menneske.

Trappen knaker igjen. Det er fru Selmer.

Hun stanser litt engang eller to for at knappe de siste knappene i morgenkjolen. Døren nedenunder åpnes og lukkes. Da har Alberte atter engang ligget for længe og bare ett er at gjøre, tørne ut med størst mulig fart og mindst mulig varmetap, klæ sig så at si inde i natlinnetet, som hun først smetter over hodet når underklærne er på.

Hvad toilettet for øvrig angår, hater hun av hjertet så vel det iskolde vand som synet av sine egne tynde armer og skarpe kraveben. Men ingen av dele står til at undgå. Speilet hænger over servanten, og fru Selmer har argusøine. Ingen mindste skygge på Albertes hals er nogensinde forblitt uavsløret en dag tilende. Mens hun vasker sig, mønstrer hun pessimistisk sin person.

Den som var anderledes, på farve og skapt og klædt, anderledes i ett og alt. Ansiktet derinde i speilet, er det virkelig hendes, det hun skal ha livet igjennem? Det er så utydelig i trækkene, hun får aldri riktig fatt i det. Håret ligger glat og ingenting tess omkring det og blotter panden altfor meget, farven er blå og grumset.

Og øinene - ja øinene har et kast. Det hænder at fru Selmer kalder det skjelen.

Alberte sætter håret op i en underlig fasong, noget, som uten at være det, fru Selmer vil og Alberte ikke vil, allikevel er en indrømmelse og et skridt mot forsoning. Så tar hun kjolen på. Der er altid maljer borte, og hun hekter ryggesløst i foret. Det går til en 
tid. En ubehagelig opgjørets dag, da den skjæve og hullete hektingen avsløres, kommer uavvendelig. Det får man la være at tænke på.

Før hun går ind i spisestuen, står hun litt utenfor døren, et øieblik bare, nogen sekunder. Hun overvinder noget, skyter hjertet op i livet.

Så går hun ind til fru Selmer og den nye dagen. 


\section{Alberte e Jakob}

Cora Sandel

Tradução do norueguês:

Fabiana Botrel

\section{I}

O relógio da igreja brilha como a lua de madrugada.

Ele bate e pequenas chamas fracas nascem no escuro e queimam foscas, perdidas na sua infinidade, solitárias e dispersas.

O relógio bate de novo e as chamas fracas tornam-se várias, aglomeram-se, formam linhas e quadrados. Vida se mexe entre elas, um sino de cavalo toca, ouve-se talvez uma carroça vazia sacolejando aqui e ali atrás de um cavalo em uma rua de terra batida. Em algum lugar alguma coisa cai no mar respingando água, uma corrente é arrastada. Sons de remos e forquetas rangendo surgem do escuro, um barco bate contra uma armação de madeira fazendo um barulho abafado, pés pesados em galochas pisam forte em um cais, alguém grita algo.

$\mathrm{O}$ apito de um barco a vapor uiva a oeste no fiorde. Lanternas vermelhas e verdes deslizam devagar na escuridão. Correria com cabos no porto Novo, no porto Velho o barco a vapor Sul do Fiorde, que sai às seis horas, toca o sinal, ávido para a partida. As oito lâmpadas em forma de arco na rua do Fiorde flamejam pálidas em fila, com exceção da que está sempre quebrada perto da Louise na Esquina. E janelas, acesas em um piscar de olhos, quadrados claros e fortemente iluminados, surgem uma atrás da outra, formando novas linhas e quadrados.

O relógio badala forte uma vez a cada quinze minutos, quatro vezes a cada hora e depois bate as horas em alta velocidade. E o alfaiate Kvandal, que toca trombone na orquestra da União dos abstêmios, pratica antes de abrir a loja. Entre longas pausas, ele tira um tom solitário e trêmulo. Esses tons pertencem aos sons matinais e com ventos favoráveis chegam até a Cidade Alta.

Se nevou durante a noite, o limpa-neves abre o caminho com grande espetáculo de um canto ao outro da cidade, com seus seis cavalos, gritos e chicotadas e Ola Paradis no comando. O tráfego está oficialmente aberto, agora é só juntar-se ao movimento. O padeiro Teodorsen aparece na sua escada.

Não se vê na penumbra, mas sabe-se que ele tem farinha no bigode e nas calças. Levanta o olhar examinando o tempo. Dentro da padaria a senhora Teodorsen, de gorro 
e luvas ${ }^{2}$, arruma os pães quentes, que esperam no postigo que dá para a cozinha, e os expõe inclinados em uma prateleira. O padeiro Teodorsen se sacode e diz “brrr"! Então abotoa o casaco até o pescoço, pega a pá de neve no cantinho ao lado da porta e começa a tirar a neve, abrindo caminho pela calçada até a rua para que as pessoas possam entrar.

A música do alfaiate Kvandal silencia. Sombras deslizam entre as casas e os sininhos nas portas das lojas tocam. Na janela das irmãs Kremers mãos colocam ordem em rolos de fitas coloridas, chapéus em mostruários, vestidos de batizado, enfeites para noivas e cadáveres. E lá vem a senhorita Liberg, no seu passeio matinal, e o velho Stoppenbrink andando, o adjunto Bjerkem com livros de redação debaixo do braço a caminho da escola e a parteira Jullum voltando para casa. Um novo dia já começou, não há dúvida.

Pode ser durante o período escuro ${ }^{3}$ com a aurora boreal, o céu estrelado e um frio que faz a neve estalar alto sob os pés. Pode ser um dia com vento úmido vindo do sudoeste e chuva, ruas negras e escuridão. Nesses dias os cata-ventos da torre da igreja guincham e os enfeites dourados na frente das padarias do Teodorsen e do Øvre tinem terrivelmente.

Também pode ter luar.

Mas o que mais tem é muita neve. Que finaliza, atenua, entristece tudo, forma, cor e som.

Quando acorda de manhã, Alberte está aconchegada e aquecida. É a única hora do dia em que não tem frio. Uma calma enorme, morna, toma conta de seus membros, uma paz corporal que é a melhor coisa do mundo.

Está deitada reta, com as pernas esticadas.

Toda a cama está aquecida e é como se seu corpo tivesse se desenrolado, como se um casco ao redor dele tivesse se rompido.

Ela se alonga, sente o corpo flexível e macio e tem a possibilidade de se ocupar com seu próprio calor frivolamente. Às vezes, presunçosa, coloca um pé para fora da coberta só para senti-lo ficar quente de novo assim que o puxa de volta.

À noite ela fica enrolada debaixo da coberta durante horas, entortada por uma geada interna. Com os joelhos dobrados até a barriga e os braços cruzados sobre o peito, ela se faz o menor possível. O frio, alojado no alto das costas entre as escápulas, lateja como

2 No original, pulsvanter. Luvas com dedos curtos e abertos, ou sem dedos, que aquecem a mão e o pulso sem prejudicar o movimento.

3 No original, morke. Refere-se ao morketid, o período do inverno no norte da Noruega em que o sol não nasce, deixando os dias escuros. No fenômeno oposto durante o verão, o sol não se põe, o que resulta no "sol da meia-noite". 
dor. Ela o sente no corpo o dia todo e ele a acompanha até a cama. Seus pés são como blocos de gelo que não fazem parte dela e ela fica tensa e dolorida da posição curvada.

Pouco a pouco ela desliza para um tipo de torpor consciente. Seu corpo, gelado mas anestesiado e sem sensação, adormece. O cérebro lá em cima na cabeça está ocupado com seus próprios pensamentos.

O tempo passa, horas. Através de uma teia de sonho semiconsciente, ela escuta o relógio da igreja.

O calor vem de súbito. Vem como uma onda de febre. Ela estica as pernas, como se estivesse a livrar-se de um instrumento de tortura - relaxa os músculos como depois de um grande esforço. Deitada, como se estivesse embriagada, sente o sono tomar conta.

Quando acorda, ela ouve. Alguma coisa tem que acontecer, o relógio da igreja bater, o alfaiate Kvandal começar a tocar, o barco a vapor Sul do Fiorde dar o sinal. Ela precisa saber que horas são e por quanto tempo pode ficar deitada sentindo-se bem. Mas o Sul do Fiorde dá o sinal três vezes, o relógio da igreja tem a irritante característica de dar apenas uma badalada tanto no primeiro, no segundo e no terceiro quarto de hora, e o alfaiate Kvandal está submetido à natureza humana - não é de forma alguma pontual. Sim, há manhãs em que ele falha.

Finalmente acontece algo em que se pode confiar, a escada range sob Jensine, que está descendo. Então ouve-se a porta do escritório e um barulho distante de carvão sendo remexido. Jensine está acendendo a lareira, primeiro lá, depois na sala de jantar.

Alberte pensa em todos aqueles que diariamente acendem o fogo de manhã. A brasa vermelha através da porta da lareira, o som crepitante do fogo, não são esses símbolos de toda a felicidade da vida? Calor é vida, frio é morte. Alberte é adoradora do fogo no sentindo mais completo e primitivo da palavra.

O calor faz todo o resto possível.

Calor e o frio incômodo nas costas acaba. Mãos e pés ganham vida. Fica-se mais audacioso, mais animado. Os membros se desprendem do corpo em movimentos mais livres e belos, é como vestir uma roupa com caimento perfeito. Tem-se vontade de falar e rir, bem como de sentar-se quieto e se ocupar com uma coisa ou outra.

Não se tem mais o rosto violeta. Se é uma pessoa nova.

A escada range de novo. É a senhora Selmer.

Ela para uma vez ou duas para abotoar os últimos botões do penhoar. A porta de baixo é aberta e fechada. Então Alberte perdeu a hora mais uma vez e só há uma coisa a 
fazer, pular da cama com a maior rapidez e a menor perda de calor possíveis, vestir-se por debaixo da camisola, por assim dizer, que ela só tira pela cabeça depois de que toda a roupa de baixo está no lugar. No que diz respeito à toalete, ela odeia do fundo do coração tanto a água gelada quanto a imagem de seus próprios braços finos e da clavícula pontiaguda. Mas não há como evitar. O espelho está pendurado acima da pia e a senhora Selmer tem olhos de águia. Nenhuma manchinha no pescoço de Alberte passa desapercebida. Enquanto se lava, observa pessimista sua pessoa.

Aquela que é diferente, na cor, na figura e na vestimenta, diferente em tudo. O rosto lá dentro do espelho é mesmo dela, aquele que terá durante a vida toda? É tão indistinto nos traços, ela nunca o consegue apreender. O cabelo cai liso e não ajuda em nada, expõe muito a testa, a cor é azul e turva.

Os olhos - ah sim, os olhos têm algo. O que a senhora Selmer às vezes chama de alma.

Alberte faz um coque desajeitado que, sem ser o que a senhora Selmer quer e o que Alberte não quer, ainda assim é uma admissão e um passo na direção de uma reconciliação. Então coloca o vestido. Há sempre colchetes difíceis de alcançar e ela abotoa o forro de qualquer jeito. Vai chegar a hora. O dia inconveniente do ajuste de contas em que o abotoamento torto e cheio de buracos será descoberto, vai chegar sem piedade. Nisso evita-se pensar.

Antes de entrar na sala de jantar, ela para em frente à porta por um momento, apenas alguns segundos. Ela supera algo, toma coragem.

Então vai ao encontro da senhora Selmer e do novo dia. 